\title{
Total Quality Management Systems in the Hellenic Public Administration: A Case Study on the Common Assessment Framework Application
}

\author{
Tsimboukidou Irene ${ }^{1}$, Dionysopoulou Panagiota ${ }^{2} \&$ Mylonakis John $^{3}$ \\ ${ }^{1}$ Visual Art Teacher, Greek Ministry of Education, Religious Affairs, Culture and Athletics, Greece \\ ${ }^{2}$ Head of the Directorate of Quality and Efficiency of the Greek Ministry of Education, Religious Affairs, \\ Culture and Athletics, Greece \\ ${ }^{3}$ Economist, Ministry of Finance, Greece \\ Correspondence: Dionysopoulou Panagiota, 11 Fornezi str., Kallithea, 17675, Athens, Greece. Tel: \\ 30-210-344-3047. E-mail: yoldi@minedu.gov.gr
}

Received: May 31, 2013 Accepted: June 13, 2013 Online Published: September 29, 2013

doi:10.5539/par.v2n2p124

URL: http://dx.doi.org/10.5539/par.v2n2p124

\begin{abstract}
The application of the Quality Management System in the Public Sector requires established objectives and continuous improvement aimed at citizens' satisfaction. Therefore, more empirical evidence is needed to meet citizens' requirements. The main quality tools used are: Management by Objectives, Indicators Measuring Efficiency and Effectiveness, the Common Assessment Framework and the Quality Certification through ISO. The CAF consists of nine criteria and 28 sub-criteria for evaluation. Each criterion involves a field or administrative aspect of reality that is accessed to determine whether it meets the stated requirements of the CAF. The paper examines the characteristics, the aim, the methodology and the implementation schedule of Total Quality Management introduced in the Greek Public Administration in 2004 by Law 3230/2004. Furthermore, the paper presents a case study in which the Common Assessment Framework was implemented in the Central Administration of the Ministry of Education, Religious Affairs, Culture and Athletics in Greece between the years 2010 and 2012. The Total Quality Management System yields multiple benefits. Of basic importance are the internal benefits that arise from better internal functioning of Public Administration. Most significant are the benefits that result from the relationship between Public Administration and external environment. This improves transactions between the administration and the public.
\end{abstract}

Keywords: public administration, quality management, common assessment framework, ministry of education, Greece

\section{Introduction}

It has been nearly 10 years since Total Quality Management was introduced to Greece's Public Administration. Total Quality Management, based on Law 3230/2004 instituted, in contrast to the previous forms of administration, the involvement of all members of staff in the production process. It focused first and foremost on quality, rather than the result. Law 3230/2004 introduced the meaning of self-management and quality in Greece's public administration.

The changes that resulted from the implementation of this law in the day-to-day operation of the public administration can be found in (a) the decision-making process which involved the staff and the management, (b) the dissemination of information, in which the flow of information is not only vertical (from the top and going down) but horizontal, and (c) the coordination that is aimed at the continuation and synchronization of the procedures all the way through to the end. To successfully achieve the implementation of Total Quality Management, the law recommends four quality management tools: Management by objectives, Indicators Measuring Efficiency and Effectiveness, the Common Assessment Framework (CAF) and the quality certification through ISO (Table 1). 
Table 1. Tools for measuring services quality in public administration

\begin{tabular}{llll}
\hline \multicolumn{1}{c}{$1^{\text {st }}$ Tool } & \multicolumn{1}{c}{$2^{\text {nd }}$ Tool } & \multicolumn{1}{c}{$3^{\text {rd }}$ Tool } & \multicolumn{1}{c}{$4^{\text {th }}$ Tool } \\
\hline Management by & Indicators for measuring & Common Assessment & Quality Certification \\
Objectives & quality and efficiency & Framework (CAF) & under ISO measurement \\
\hline
\end{tabular}

As shown in Table 1, there are 4 main tools required for Total Quality Management

The legal framework of Total Quality Management System is described in the Law No. 3230/2004 (Management by objectives, measurement of efficiency and other provisions), and the Presidential Act 259/2005 (Establishment of Administration of Quality and Efficiency).

\section{Presentation of the Four Tools Measuring Quality in the Public Administration}

\subsection{Management by Objectives: The Indicators for Assessing Quality and Efficiency (Tools 1 \& 2)}

\subsubsection{Context}

The provisions outlined in Article $1 \S 2$ of Law No. 3230/2004, establish the system for measuring the effectiveness and efficiency in the public administration. The purpose of this measurement is to evaluate public administration services and to promote the enhancement of transparency, the better utilization of available resources and the overall improvement to make public services more efficient for citizens. Article 6 of the same law, foresees the creation of a special Directorate of Quality and Efficiency units at all government ministries. The Directorate of Quality and Efficiency is responsible for measuring efficiency and effectiveness, for assessing the results and drafting concrete proposals aimed at improving the service units.

Article 1 of Law No. 3230/2004 explicitly outlines the effectiveness and efficiency concept as follows: Effectiveness is defined as the ability of public administration to fulfill its goals in due time and efficiency is the ability to achieve the greatest possible extent of objectives by the lowest possible cost.

Furthermore, Article 3 of the same law explains the management by objectives systems and how this is applied in practice:

a) The political leadership of each Ministry defines and disseminates the strategic objectives for each subsequent year.

b) The administrative leadership at each hierarchical level determines the specific objectives to take effect the following year.

c) Indicators are used to evaluate effectiveness and efficiency.

As stated in Article 5 of the law, the measures of effectiveness and efficiency are divided into two main categories: General indicators and Specific indicators. The legislator defines the general indicators as "the response time to citizens' requests, the satisfaction rate of complaints lodged, the application of new technologies, and the management and quality of service".

As regards specific indicators, these are defined separately by each directorate based on the type of services they provide. Under Article 5, paragraph 4 of law No. 3230/2004, a joint ministerial decision issued by the ministers of interior and education, outlines the general indicators and the specific indicators, the method of measuring and the frequency of measurement, as well as any other matter that is pertinent.

\subsubsection{Methodology}

The Management by Objectives and measuring quality and efficiency performance should be applied according to the following methodology:

In his decision the Minister determines and announces the strategic objectives as regards the services for the upcoming year. The Minister's decision is expected no later than December 20 of each calendar year. With this decision: the priority of each objective, the indicators for measuring results and a timetable for implementation are determined. Thereafter, each General Division is required to reflect its mission (as stated in the description of responsibilities) and its goals, striving for effective and efficient completion of tasks within the strategic objectives of the ministry as appropriate.

Each Directorate is required to define and describe the responsibilities and goals as part of the operational objectives of the General Division to which it belongs. The Directorate then sets goals for each individual action. These are goals that will result from its responsibilities, taking into account the strategic objective of the Minister 
and the operational objective of the General Division to which it belongs, assuming the distribution of its objectives in its departments and defining the responsibilities of actions for each employee.

Each Directorate measures for each activity a special indicator by collecting the necessary data. Performance must reflect reliable, measurable and comparable results. The Directorate should immediately appoint two employee representatives, who have knowledge and experience of the Directorate, to coordinate and run the Management by Objectives system in collaboration with the Directorate of Quality and Efficiency of their institution and the Directorate of Quality and Efficiency of the Ministry of Interior.

To ensure the effective implementation, workshops should be organized in collaboration with the Ministry of Interior to inform the heads of General Divisions, Directorates, Departments, representatives and in general all employees of the institution.

The monitoring of the implementation should be made by the heads of the Directorates at regular intervals, which should not be longer than three months. Certainly, the Directorate can revise and redefine goals if new data arise. In late November of each calendar year, the Directorate drafts a detailed report on the action and sends it to the Directorate of Quality and Efficiency of its institution.

The Directorate of Quality and Efficiency of each Ministry reports the results of the institution and submits this report to the Directorate of Quality and Efficiency of the Ministry of Interior.

\subsubsection{Time Schedule}

The management by objectives should apply to an annual timetable (Article 3, paragraph 3, Law 3230/2004). The frequency of measuring the indicators will be determined by a joint ministerial decision issued by the Minister of Interior and any other Ministers who may be involved (Article 5, par.4, 1, 3230/2004).

The total implementation time takes 12 months. Specifically, in the first phase, the Directorate of Quality and Efficiency of the Institution reminds the Minister's office to issue the decision determining the strategic objectives that must be announced to all the general divisions. In the second phase, each Directorate identifies its individual objectives. In the third phase, the heads of the Directorates monitor the implementation. In the fourth phase, the implementation is completed by the Directorates (December of each year) and reports are sent directly to the Directorate of Quality and Efficiency. In the fifth phase, the annual debriefing report of the institution is processed. In the sixth and last phase, the report is submitted to the Directorate of Quality and Efficiency of the Ministry of Interior.

Furthermore, the results of measuring the effectiveness and efficiency by the Directorates are sent in December to the Directorate of Quality and Efficiency of the institution that is legally responsible to edit the report, outlining the outcomes as regards the institutions' actions and services. The report is then submitted to the relevant Directorate of Ministry of Interior (Table 2).

Table 2. Schedule plan for the implementation of management by objectives and measuring effectiveness and efficiency

\begin{tabular}{|c|c|c|}
\hline Phases & Timetable & Activity \\
\hline \multirow[t]{3}{*}{$1^{\text {st }}$ phase } & November & Ministry is notified by the Department of quality \& efficiency \\
\hline & December & Ministry announces the institution's strategic objectives \\
\hline & By December & Ministerial Decision is Issued \\
\hline $2^{\text {st }}$ phase & January & Implementation \\
\hline \multirow[t]{5}{*}{$3^{\text {st }}$ phase } & January-March & Monitoring \\
\hline & March- May & \\
\hline & May-July & \\
\hline & July-September & \\
\hline & Sept.-November & \\
\hline $4^{\text {st }}$ phase & December & Completion of procedures by the Directorates. Drafting of the reports \\
\hline $5^{\text {st }}$ phase & January-February & Editing of the reports \\
\hline $6^{\text {st }}$ phase & March & Reports submitted to the Ministry of Interior \\
\hline
\end{tabular}

As shown in Table 2, there are 6 phases for measuring effectiveness and efficiency 


\subsection{Common Assessment Framework (Tool 3)}

\subsubsection{Context}

The Common Assessment Framework (CAF) is a total quality management tool, influenced by the Standard of Excellence of the European Foundation for Quality Management (EFQM) and the standard of the German University of Administrative Sciences Speyer. According to the CAF, the best results in organizational performance, customers/citizens and society depend on the leadership, strategy and planning, human resources, partnerships, resources and administrative procedures. The philosophical foundation of CAF can be detected in action research (participatory action research, Freire, 1972, 1985; Habermas, 1972). The CAF is a holistic analysis of organizational performance approaching it from different perspectives simultaneously. The first pilot version was presented in May 2000 and then revised in 2002. Since 2000 to 2005, some 900 European public administration services have been using the CAF to improve their operations. There is also a growing interest from outside Europe - from China, the Middle East and from the Dominican Republic and Brazil. More than 300 users of the CAF attended the first European conference in Rome in 2003 and the second conference in Luxembourg in 2005.

The CAF is offered as an easy-to-use tool to assist public sector organizations across Europe apply total quality management techniques and improve their performance. The CAF provides a framework for self-evaluation that was specifically designed for public sector organizations. Although the CAF is mainly focused on evaluating the performance of administration so as to improve it, the ultimate goal is to make a lasting contribution of good governance. Thus, the evaluation of performance refers to the

ability to respond to citizens' needs and accountability, the ability to communicate on the political level, the ability for stakeholders to participate and to balance their needs, the ability to provide excellent service, the ability to save on costs, the ability to achieve objectives, and the ability to modernize, innovate and change.

\subsubsection{Methodology}

The CAF consists of nine criteria and 28 sub-criteria for evaluation. The structure of the nine criteria identifies the main points to be considered in any organizational analysis. Criteria 1 through 5 concern the conditions of an organization. These conditions determine the "what" and "how" of the organization. Criteria 6 through 9 concern organization outcomes, regarding key concepts, such as: citizens/customers, people, society, results through measurements, and satisfaction from the operation of a public organization. These criteria are based on the use of indicators for measuring results.

The 28 sub-criteria, which identify the main issues to consider when evaluating an organization, are explained with examples that express their nature. Each example involves a field or administrative aspect of reality that is accessed to determine whether it meets the stated requirements of the CAF.

\subsubsection{Time Schedule}

One application of the CAF may last about 4 months. Specifically, during the first phase, which can last up to 4 weeks, the scope is determined and the action group is informed (Table 3). During the second phase, which can last up to 4 weeks, tasks are distributed and the inner workings of the group are determined. During the third phase, which can last 8 weeks, data is collected and scored and an initial draft of a report is prepared. Finally, during the fourth phase, which may last one week, the final report proposing improvement measures is drafted.

\subsection{ISO Certification (Tool 4)}

\subsubsection{Context}

The ISO is the acronym for the International Standardization Organization. It is the largest international organization for standardization. Founded in 1947, the ISO developed standards to cover many different industry sectors. Today, it comprises the national standardization bodies of 148 countries. The ISO certification procedures are followed by 2,981 technical corporate bodies (technical committees, subcommittees, working groups and study groups). In Greece, the ISO is represented by the Greek Organization for Standardization (ELOT).

There are more than 14,000 international standards of the ISO and among them is the ISO 9000 series, which includes standards related to the creation (development) and implementation of Total Quality Management Systems for organizations of all types. 
ISO 9001:2008 is strongly focused on continuous improvement of overall performance and efficiency of an organization aiming to serve the needs and expectations of stakeholders in the best manner. The ISO 9001:2008 is based on applying a continuous improvement cycle (the Deming cycle) consisting of four distinct parts.

Table 3. Schedule for the implementation of the CAF duration

\begin{tabular}{|c|c|c|c|}
\hline Phase & Time Table & Title activity & Activity \\
\hline \multirow{3}{*}{$\begin{array}{l}1^{\text {st }} \text { Phase } \\
\text { The support of the institution }\end{array}$} & $1^{\text {st }} \quad 2$ week duration & Group training sessions & Meeting appointments \\
\hline & & & $\begin{array}{l}\text { within working hours, } \\
\text { appointment of the project } \\
\text { leader }\end{array}$ \\
\hline & $2^{\text {nd }} 2$ week duration & $\begin{array}{l}\text { Determination of action } \\
\text { group }\end{array}$ & Conduct of seminars \\
\hline \multirow{3}{*}{$\begin{array}{l}2^{\text {nd }} \text { Phase } \\
\text { Distribution of Functions }\end{array}$} & $3^{\text {rd }} 1$ week duration & Determination of the inner & Ministerial Decision \\
\hline & & $\begin{array}{l}\text { workings to be developed by } \\
\text { the group }\end{array}$ & \\
\hline & $4^{\text {th }} 3$ week duration & Informed consent & $\begin{array}{l}\text { Information, stakeholders } \\
\text { consent and permission } \\
\text { approval }\end{array}$ \\
\hline \multirow{6}{*}{$\begin{array}{l}3^{\text {rd }} \text { Phase } \\
\text { Data collection } \\
\text { Data analysis }\end{array}$} & $5^{\text {th }} 2$ week duration & Methodology of procedures & Sampling issues interview \\
\hline & & & data collection \\
\hline & & & \\
\hline & $6^{\text {th }} 2$ week duration & Data collection & Documentation \\
\hline & $7^{\text {th }} 2$ week duration & $\begin{array}{l}\text { Structuring and evaluating } \\
\text { the data- sampling }\end{array}$ & $\begin{array}{l}\text { Validity and reliability check } \\
\text { of data }\end{array}$ \\
\hline & $8^{\text {th }} 2$ week duration & Data analysis & $\begin{array}{l}\text { Statistical analysis, key } \\
\text { findings, identification of } \\
\text { indicators }\end{array}$ \\
\hline $\begin{array}{l}4^{\text {th }} \text { Phase } \\
\text { Reporting }\end{array}$ & $9^{\text {th }} 1$ week duration & Outcome Reporting & $\begin{array}{l}\text { Submission of final report, } \\
\text { future directions }\end{array}$ \\
\hline
\end{tabular}

As shown in Table 3, the application of CAF lasts about 4 months

\subsubsection{Methodology}

The ISO 9001:2008 certification procedures require the application of two phases: During the first phase "audit trial" five stages are 1) Diagnostic research, 2) Quality System Design, 3) Quality System Documentation, 4) Quality System Improvement and 5) Aims set and implementation.

The second phase of certification is achieved under the condition that the audit trial process proves that the management system of the organization is compatible and compliant with the requirement of standards of the ISO 9001:2008. If this is the case, the ISO certification body issues a written statement and awards the organization the ISO 9001:2008 certificate. The certified organization is listed on the certified customers of ISO organization. This process is called registration (Registration) and it occurs immediately after certification.

\subsubsection{Time Schedule}

The time required to complete an ISO 9001:2008 certification procedure directly depends on several factors, like a) the size of the unit under certification, b) the allowed time for completing procedures, c) various quality and quantity factors regarding the organization to be certified, and d) the approved budget. The first phase of the audit trial may last as long as a year when referring to an organization consisting of approximately 50 employees. The amount of time required to complete the second phase depends on the certification body (Table 4). 
Table 4. Phases of the ISO certificate

\begin{tabular}{ccc}
\hline Phases & Steps & Action to be done \\
\hline $1^{\text {st }}$ phases Audit trial & 1 & Diagnostic research \\
& 2 & Quality System Design \\
& 3 & Quality System Documentation \\
& 4 & Quality System Improvement \\
$2^{\text {nd }}$ phase Certification & 5 & Aims set and implementation \\
\hline
\end{tabular}

As shown in Table 4, ISO Certificate requires 2 phases

\subsection{The Relationship between Management by Objectives, the Indicators for Assessing Quality and Efficiency, CAF and ISO}

There is a substantial relationship between the four tools. Therefore, the strengths or weaknesses that highlight a CAF application could a) generate future objectives and goals (so to rectify weaknesses) and b) designate and suggest indicators for assessing quality and efficiency (so to further reinforce strengths). Furthermore, a potential case of top quality results, from indicators for assessing quality and efficiency may claim for an ISO certification.

\section{From CAF to Innovation}

\subsection{The Case Study}

This part of the paper will describe how the application of the CAF led to a significant innovation, initiated and implemented by the education ministry and subsequently praised by the international community. Firstly, we will explain the reasons the CAF was applied by the education ministry and how it was implemented. Later the paper will analyze the CAF results, which ultimately led to the innovation, which was not only successful on a national level, but also recognized internationally. More specifically, this particular case concerns the implementation of the CAF by the Directorate of Organizing and Conducting Examinations in 2010, which resulted in the innovation during the following academic year. The decision to implement the CAF stemmed from concerns about the level of efficiency associated with the administration of the Pan-Hellenic University Entrance Examinations (known in Greek as "Panellinies"). The university education examinations, which are held annually, are considered one of the most important tasks administered and overseen by the education ministry. The ministry's three main directorates oversee all the procedures related to the examinations. About 60 people in these directorates work each academic year to administer the examinations and ensure the smooth operation of the entire application procedure. The three directorates are: the Directorate of Organizing and Conducting Examinations, the Directorate of Software Development and the Directorate of Information Systems' infrastructure. They represent the education ministry's three large directorates as regards the number of staff.

As regards the examination, an estimated 200,000 secondary school graduates sit the examinations each year. In 2009-2010, a total 182,000 students from general and technical secondary schools nationwide sat the examination. Of these, 18,100 were students falling into one of several special categories. These categories include students of large families with four or more children (about 7,000), religious minorities (Muslims from Thrace), Greeks abroad (2.500) disabled (about 2,000), foreigners $(5,500)$, athletes $(800)$ and those awarded scholarships (about 1,000).

As regards staff, responsible for administering the examination, are 2,000 specialists worked on 170 local prefectural committees in order to process each and every application for the academic year 2009-2010. 60 specialized staff members working centrally. What is more, as regards funding, a total 23,334,483 Euros was spent on the examinations during the academic year 2009-2010.

As regards the application procedure, it was the following for the candidates who fall in the general categories (seniors from general and technical secondary schools): They submit an application at their nearest prefectural-based committee (there are 170 such committees all over Greece) of the education ministry's Secondary School Education Directorate. These committees are responsible for the processing of all the applications. A list of the application requirements are electronically sent to the Education Ministry. At the ministry the three Directorates (the Directorate of Organizing and Conducting Examinations, the Directorate of 
Software Development and the Directorate of Information Systems' infrastructure) were responsible for the analysis of data and the announcement of the results.

As regards the application procedure, it was the following for the candidates who fall in special categories (seniors of large families, religious minorities, Greeks abroad, disabled, foreigners, athletes, and those awarded scholarships): They must apply in writing to one of the education ministry's four committees, which fall under the jurisdiction of the Directorate of Organizing and Conducting Examinations. These four committees are responsible for processing and examining the applications. Their goal is to facilitate students who fall into one of the special categories: disabled, foreigners, Greeks abroad and athletes. Their applications would be recorded and filed electronically. The Foreign Ministry would also examine all the applications submitted by foreign students who were granted a scholarship to study at a Greek university.

From the above description, it is easy to realize just how much work was involved as regards the successful administration of the university entrance examination. Probably the biggest obstacle to success was the incredibly high cost involved, the enormous amount of paperwork that must be filed and the lengthy procedures, as well as the many delays and the even greater amount of complaints from frustrated candidates.

\subsection{The Need of CAF Application}

For all these reasons and given that the improvement of overall public services offered by the Education Ministry was the forefront (the ministry's basic mission), officials decided in 2010 to start implementing the CAF in the Directorate of Organizing and Conducting Examinations. Members of staff and the public were called on to assess the procedure by answering a special questionnaire. The results were carefully analyzed and reported.

Overall the main results of CAF application addressed a number of important points, including the success in achieving reliable and transparent entrance examinations, success in applying effective management strategy procedures and the need to cut costs. Specifically, the results suggested the need for the creation of an electronic (web-based) application procedure, as well as, the need for the administration, as a whole, to start setting goals and working together with the various offices of the education ministry (Table 5).

Table 5. Interpretation of core findings

\begin{tabular}{|c|c|c|c|c|c|c|}
\hline \multicolumn{7}{|l|}{ Justification } \\
\hline $\begin{array}{l}\text { Criterion } \\
\text { number }\end{array}$ & $\begin{array}{l}\text { Criterion } \\
\text { number }\end{array}$ & $\begin{array}{l}\text { Criterion } \\
\text { number }\end{array}$ & $\begin{array}{l}\text { Criterion } \\
\text { number }\end{array}$ & $\begin{array}{l}\text { Criterion } \\
\text { number }\end{array}$ & $\begin{array}{l}\text { Criterion } \\
\text { number }\end{array}$ & Criterion number \\
\hline 1.2 .6 & 2.4 .4 & 4.5.1 & 4.5.2 & 4.5.3 & 5.2 .6 & 5.3 .1 \\
\hline
\end{tabular}

Justification

$\begin{array}{lllllll}\text { Criterion } & \text { Criterion } & \text { Criterion } & \text { Criterion } & \text { Criterion } & \text { Criterion } & \text { Criterion number } \\ \text { number } & \text { number } & \text { number } & \text { number } & \text { number } & \text { number } & \end{array}$

$\begin{array}{lllllll}1.2 .7 & 1.4 .1 & 2.2 .1 & 2.2 .3 & 2.4 .3 & 3.3 .4 & 5.1 .5\end{array}$

6.2.3 $\quad 6.2 .4 \quad 6.2 .6 \quad 9.1 .3$

THE THIRD CORE FINDING - Need for empower internal cooperation

Justification

$\begin{array}{llllll}\begin{array}{l}\text { Criterion } \\ \text { number }\end{array} & \begin{array}{l}\text { Criterion } \\ \text { number }\end{array} & \begin{array}{l}\text { Criterion } \\ \text { number }\end{array} & \begin{array}{l}\text { Criterion } \\ \text { number }\end{array} & \begin{array}{l}\text { Criterion } \\ \text { number }\end{array} & \begin{array}{l}\text { Criterion } \\ \text { number }\end{array} \\ 1.1 .1 & 1.1 .4 & 7.1 .3 & 7.2 .3 & 7.2 .10 & 9.2 .1\end{array}$

As shown in Table 5, the results suggested the creation of electronic application and administrative procedures

The finalization of the report in December 2010 marked the formal completion of the implementation of the CAF. But the Education Ministry did not stop there. The Deputy Education Minister at the time was interested in promoting the electronic services offered by the ministry. This was an opportunity to proceed with the first 
finding of the CAF results. The vision, therefore, of the education ministry's political leadership for the development of electronic (web-based) services, found all the necessary evidences outlined in the report.

\subsection{The Innovation}

The 2011 university entrance examinations heralded a new strategy -one based on the electronic (internet-based) services that were introduced for the processing of the applications for entry into tertiary education. The idea of this new strategy, which was emerged from the base (with the help of the staff that is), was supported wholeheartedly by the political leadership of the education ministry.

This new tool that was named the "Web-entrance application procedures for Higher Education in Greece" was created to help improve the overall quality of the services offered by the education ministry and to facilitate entry into tertiary education of about 200,000 candidates each year. The tool was assigned by the Deputy Minister to be developed in collaboration of the three Directorates. It was primarily aimed at: a) cost-cutting b) reducing the bureaucracy involved and improving the level of efficiency, as well as c) increasing the level of trust between the public sector (in this case the education ministry) and the citizens. The benefits were registered and the results were compared to previous years. The benefits were many and included a streamlined procedure that required less time, energy and funds to implement (Table 6).

Table 6. The benefits of innovation

\begin{tabular}{|c|c|c|}
\hline Cost before the innovation & Cost after the innovation & Benefits \\
\hline 23.334.488 million $€$ & 13.758.308 million $€$ & $\begin{array}{c}9.576 .180 \text { million } € \\
\text { earned }\end{array}$ \\
\hline Time required before & Time required after & Benefits \\
\hline 3 months & Less than 1 month & $\begin{array}{c}2 \text { months less } \\
\text { working period } \\
\text { earned } \\
10 \text { days more }\end{array}$ \\
\hline $\begin{array}{l}20 \text { days available period for } \\
\text { servicing candidates }\end{array}$ & $\begin{array}{l}30 \text { days available period for } \\
\text { servicing candidates }\end{array}$ & $\begin{array}{l}\text { available time for } \\
\text { servicing } \\
\text { candidates }\end{array}$ \\
\hline Personnel before the innovation & Personnel after the innovation & Benefits \\
\hline 60 people & 30 people & $\begin{array}{l}30 \text { people. Less } \\
\text { personnel in half }\end{array}$ \\
\hline Other facts & Other facts & Benefits \\
\hline $\begin{array}{l}\text { Hardcopies of the applications } \\
\text { distributed nationwide }\end{array}$ & $\begin{array}{l}\text { No extra cost for the development of } \\
\text { the web application }\end{array}$ & $\begin{array}{l}\text { Saved paper, } \\
\text { printing and } \\
\text { distribution } \\
\text { expenses }\end{array}$ \\
\hline
\end{tabular}

As shown in Table 6, the benefits required less time, energy and funds to implement

Specifically, the university entrance examinations cost the state a total $23,334,488$ Euros to administer in 2009-2010, but only 13,758,308 Euros the following year when the whole procedure went online. The education ministry noted a savings of almost 10 million Euros. This amount was enough to cover the cost of employing the 526 full-time teachers' staff of the local regions of Athens for the year 2011. As regards the time involved to administer the examinations, it took three months in 2009-2010, but less than one month the following academic year when the electronic system was introduced. There were also 10 more days available to service candidate students. As for the procedure, the following should be highlighted: The application procedure was fully electronic (web-based) during the academic year 2010-2011. Hard copy application requirements were only required from students from large families with four or more children and from students who fall in another special category. As regards candidates from these other special categories, they were required to submit a 
handwritten application in the previous years. Now their applications are also filed electronically and any hard copy application requirements are sent by mail (Table 7).

Table 7. Procedures before and after innovation

\begin{tabular}{|c|c|c|c|c|}
\hline \multicolumn{3}{|c|}{ Applications procedures before the innovation } & $\begin{array}{l}\text { Applications } \\
\text { innovation }\end{array}$ & procedures after the \\
\hline Categories & Place of attendance & Way & $\begin{array}{l}\text { Place of } \\
\text { attendance }\end{array}$ & Way \\
\hline For general & & & & \\
\hline $\begin{array}{l}\text { categories } \\
\text { (including the } \\
\text { categories of } \\
\text { candidates from } \\
\text { large families } \\
\text { and social } \\
\text { criteria) }\end{array}$ & $\begin{array}{l}\text { Application-local } \\
\text { submission } \\
\text { (lyceio)-central } \\
\text { analysis of data } \\
\text { (Ministry) }\end{array}$ & $\begin{array}{l}\text { Mixed } \\
\text { (Manuscript } \\
\text { and electronic } \\
\text { submission) }\end{array}$ & $\begin{array}{l}\text { In Web } \\
\text { (electronic } \\
\text { submission) }\end{array}$ & $\begin{array}{l}\text { Fully electronic for } \\
\text { general categories } \\
\text { (Manuscript only for } \\
\text { the candidates from } \\
\text { large families and with } \\
\text { social criteria) }\end{array}$ \\
\hline $\begin{array}{l}\text { For the rest of } \\
\text { the special case } \\
\text { categories }\end{array}$ & $\begin{array}{l}\text { Application-central } \\
\text { submission } \\
\text { (Ministry) }\end{array}$ & $\begin{array}{l}\text { Manuscript } \\
\text { plus further } \\
\text { documentation }\end{array}$ & $\begin{array}{l}\text { In Web } \\
\text { (electronic } \\
\text { submission) }\end{array}$ & Via post (hardcopy) \\
\hline
\end{tabular}

As shown in Table 7, all applications are filed electronically after the innovation

It is clear the innovation tool was successful because it significantly reduced the cost and time involved in the application procedure. It also increased the security of the action, created a trustworthy and user-friendly procedure for the applicants and cultivated a new web-based culture at the education ministry.

As a whole, this entire experience is considered invaluable. It was also of extraordinary importance for the progress made by the administration in general of the education ministry. Specifically, internal operations were strengthened and the provision of the organization became a challenge for administration.

\section{International Award}

In September 2012, the Greek Ministry of Education was invited to present at the $5^{\text {th }}$ International Conference for the CAF users "The CAF as a driving force for innovation" in Oslo - Norway, the administrative innovation that was emerged by the analysis of CAF results that was conducted in the Directorate of Organizing and Conducting Examinations, entitled as: "Web-entrance application procedures for Higher Education in Greece".

The Greek presentation was chosen to be 1 of the 18 "best administrative practices" in public services and institutions of the European Union as a result of their assessment based on the CAF in 2011.

The decision to present this initiative that promotes the good practices of the Greek Ministry of Education at an international level, undoubtedly offered benefits for the education ministry. Specifically, it strengthened cooperation between the various directorates and it established a practice of goal setting between the various directorates. Even more, this particular case demonstrated the procedures of strong work ethics and teamwork, which are the core features developed by the adoption of the Total Quality Management System by Greece's public administration.

\section{Conclusions}

Law No. 3230/2004 foresees a large number of provisions for the implementation of the "Management by Objectives System" in Greece's public sector. Specifically, the administration's role is to measure the efficiency and effectiveness of the public sector, and to assess the results and formulate specific proposals for its qualitative improvement.

This paper examined how each of Total Quality Management tools developed in the wider realm of the services were provided by the Greek of Ministry of Education, Religious Affairs, Culture and Athletics between the years 
2007 and 2012. This assessment showed how the implementation of the Common Assessment Framework served to improve one of the operations of the ministry's services and highlighted the Greek public administration at the international level.

Total Quality Management System in public administration yields multiple benefits. Of basic importance are the internal benefits that arise from better internal functioning of public administration. Most significant are the benefits that result from the relationship between public administration and external environment. This improves transactions between the administration and the public.

To conclude, the application of the Quality Management System in which objectives are established, continuous improvement is aimed and the citizen's satisfaction is sought. This can lead to better results in the short-term. In the long-term, this results in the overall business development, increased competitiveness and reliability of services.

\section{Acknowledgements}

To Fay Portoula (M.A.), civil servant in the Directorate of Quality \& Efficiency and Giannis Katopodis (M.Sc.), Head of the Directorate of Information Systems Infrastructure in the Greek Ministry of Education and Religious Affairs, Culture and Athletics.

\section{References}

Akrivos, C., \& Psaropoulos, Ch. (2008). Total Quality Management in Public Services in the field of Education. Ministry of Education, Religious Affairs, Culture and Athletics. Special Programs Application Service CSF. Retrieved from http://hdl.handle.net/10795/1336 and http://repository.edulll.gr/1336

Freire, P. (1972). Pedagogy of the oppressed. Harmondsworth, UK: Penguin.

Freire, P. (1985). The politics of education: Culture, power and liberation. Westport, CT: Bergin and Garvey.

Habermas, J. (1972). Knowledge of human interests. London: Heinemann.

Law 3230/2004. Management by objectives, measurement of efficiency and other provisions. Official Gazette No 44/A/11-2-2004.

Law 3230/2004. Management by objectives, measurement of efficiency and other provisions. Official Gazette No 44/A/11-2-2004.

Ministry of Interior. (2008). Common Assessment Framework. Athens.

Presidential Act 259/2005. Establishment of Administration of Quality and Efficiency.

Thessaloniki Business Consults Network. (2009). International Standardization Organization - Quality Systems ISO 9001: 2008. February. Thessalonica.

\section{Copyrights}

Copyright for this article is retained by the author(s), with first publication rights granted to the journal.

This is an open-access article distributed under the terms and conditions of the Creative Commons Attribution license (http://creativecommons.org/licenses/by/3.0/). 